\title{
The Features of Workshop on Friedrich-Alexander- University Erlangen-Nuremberg of Germany -- Discussion on the Development of Laboratory Reform on Mechanical Engineering Department of Shanghai University
}

\author{
Tian Yingzhong \\ School of electrical and mechanical engineering and \\ automation \\ Shanghai University \\ Shanghai 200072, China \\ troytian@shu.edu.cn \\ Luo Jie \\ School of electrical and mechanical engineering and \\ automation \\ Shanghai University \\ Shanghai 200072, China
}

\author{
Peng Liangxiu \\ School of electrical and mechanical engineering and \\ automation \\ Shanghai University \\ Shanghai 200072, China
}

Li Wei

School of electrical and mechanical engineering and automation

Shanghai University

Shanghai 200072, China

\author{
Li Long* \\ School of electrical and mechanical engineering and automation \\ Shanghai University \\ Shanghai 200072, China \\ lil@shu.edu.cn
}

\begin{abstract}
With the deepening of teaching reform in Shanghai University, Department of Mechanical Automation Engineering (DMAE) is paying more and more attention to the cultivation of students' abilities, among which the practical and innovation ability is the key indicator of the development of training programs and evaluation of teaching quality. As the important factor of students' ability training, the quality of our laboratories has a big gap with laboratories of Mechanical Engineering Department of Nuremberg University in Germany, so this paper analyzes the reasons and makes suggestions to improve it.
\end{abstract}

Keywords-Mechanical disciplines, Comparison of the laboratories, Laboratory reform

\section{INTRODUCTION}

With the deepening of teaching reform in Shanghai University, the DMAE in our college is paying more and more attention to the cultivation of students' ability, among which the practical ability and innovation ability is the key indicator of the development of training programs and evaluation of teaching quality. Compared to the students of Mechanical Department in Nuremberg University of Germany, our students have obvious gaps in theory and practice ability, especially in manipulative ability. It also leads to students' weakness on their independent analysis, problem solving and innovation ability. The reasons contain two aspects. On the one hand the practice hours for professional skills training share an insufficient rate in original training program, which leads to the result that students are deficient in using ability and problem solving. On the other hand a lack of high level laboratories also makes the students have no chance to complete the verification, comprehensive, innovative and other high level projects, and the practice teaching facilities have not been arranged, causing a lot of advanced equipment not used in undergraduate teaching.

At present, our department has noticed the problem of lacking practice teaching hours. To solve it, practice hours which can strengthen the training of professional skills for students are now gradually added in the new syllabus; meanwhile, the high level laboratory quality requires much effort to do so, "there are other hills whose stones are good for working jade”, we can work together with German side to build a high level laboratory. A high level laboratory will provide a good hardware environment for better teaching experiment and scientific research, which can improve the 
study grade, so that teachers can be engaged in high levels study and students can also participate in the high level research [1]. Improving research level can not only provide theory and application technology, but also the laboratory funding is easier to be acquired; conversely, poor laboratory conditions tie the hands of researchers, making it difficult to carry out high level study and leading to difficulties in funding sources. Gradually, it's getting increasingly difficult to update and maintain all aspects of laboratories new research, which results in a vicious circle and students also don't get a high level training.

The general level of the laboratory of Nuremberg University of Germany is top-ranking in the world. Of course, this is related to the school status but due to their closely attention to the laboratory. Nuremberg University of Germany stresses the importance of practice, so the students' manipulative abilities are very strong. Judging from my participation in their mechanical department of undergraduate experimental class, I can feel that our students have an obvious gap with German students. In contrast, because of subjective and objective reasons, most laboratories in our department are not able to meet the requirements of teaching and scientific study, leaving us helpless. If constructing high level laboratories is not realized, Shanghai University is hard to join the domestic first-class research universities; especially the school development goal is to join 985-type universities. In our college and the Department, improving the quality of our own laboratories is a task which brooks no delay.

\section{DISCUSSION}

University of Nuremberg in Germany has a kind of laboratories called "workshop", which is similar to the factory workshops of large-scale comprehensive laboratory. The laboratory is in charge of professors, and the management persons are doctor employees, and there are several high level technicians. This management structure guarantees that the integrated environment of laboratory is first-rate. Teaching and scientific research in the laboratory are mutually penetrated and complemented, and scientific research project itself is closely combined with social development and actual needs. Scientific research results can be applied to teaching in a timely manner, meanwhile the birth of new ideas and new research results also emerge. These laboratories are somewhat similar to the Shanghai University Students' metalworking workshop, but there are a lot of differences, and I will give a following example. To point out some suggestions that the laboratory of our department needs to progress; we will build all kinds of laboratories in the future to absorb their advantages, and develop our own high level laboratories with distinctive features.

First, the laboratory plan is different. For example, there is a three coordinate measuring precision workshop laboratory in the Nuremberg University South Campus of Mechanical Engineering Department and our DMAE also has one, but two similar laboratories have many differences in many aspects. The first point is the laboratory's environment and placement. The University of Nuremberg is considered to be very strict. Since it is a precision measurement laboratory, the laboratory is airtight and lustration and the laboratory environment cleaning requirements are very tight. Everyone must use professional cleaning equipment to clean shoes and clothes before entering into the laboratory. Then they would be allowed to come to a special passageway for cleaning clothes and dust in head. After that, they can enter into the laboratory whose atmosphere is slightly higher than $1 \mathrm{~atm}$. Precision measurement equipment in the laboratory is arranged in good order, and its internal environment is very clean and tidy. The bottom of the laboratory has an anti-earthquake foundation and the floor has been painted well. There are a lot of temperature sensors in the room to adjust the range of internal temperature fluctuation smaller than \pm 0.1 DEG c. The laboratory also has been equipped with a tool room, thermostatic chamber, job shop and other auxiliary rooms. The workshop has a large amount of advanced measurement equipment and third-party certified qualification and has also gained the certification of PTB [2].

In this lab, the students can carry out some experimental projects which concentrate on validation, comprehensive, development and innovation, and various laboratories can also carry out a high level cooperation mutually. Beside the three coordinate laboratory is a high level of automation lab, where has a flexible manufacturing system (FMS) production line and can finish a lot of workpieces with complex design and processing, get the coordinate measuring precision measurement, export digital full size comprehensive report, and present a certificate of quality analysis results. According to the results, we can adjust FMS production line for further processing and manufacturing to get the finally satisfactory products. At the same time, the students in the laboratory cooperation process have also achieved a high-level comprehensive laboratory manipulative ability which greatly improves their comprehensive ability. Compared to the workshop lab, the coordinate precision measurement laboratories in our department, planning and design have large differences. Laboratory has no demand for air cleanliness and cleaning tools for personnel before them entering into the room. Temperature control is quite a little unreasonable and there is no auxiliary tool room. Only anti-earthquake foundation is a bit same. Another problem is mouse in the lab which often gnaws down laboratory equipment.

Secondly, there is a great difference in the sources of laboratory funding. Their laboratory maintenance funding sources are adequate and come from many ways such as government investment, school investment, enterprise investment, personal or enterprise donations, and etc. Therefore, it is unnecessary to worry about funds in general. But the use of funds is extremely strict. The professor is in charge of the use of funds that school would not interfere, and conduct a standard audit, evaluation [3]. Our department has a lot of restrictions. The single source of funding for laboratory leads to insufficient of many labs maintenance funds. There are also aging problems of three coordinate measuring room's equipment and maintenance is not timely update. Therefore, taking more efforts to increase investment of laboratory maintenance is necessary.

The third point is lab position setting and responsibilities. University of Erlangen Nurnberg's three coordinate precision measurement laboratory is in charge of Professor, including laboratory's construction, management, project application and 
construction to the school and the government proposed laboratory construction project application, the arrangement of experiment teaching task and so on. Assistants of professor are to complete the research and teaching tasks, such as participating in research experiments, assisting professors to prepare courseware, assisting students in the experimental class, correcting student reports, etc. Laboratory engineers and technicians' responsible is the lab operation management and technical work, such as the preparation, equipment maintenance and repair, and ensure equipment's good condition in experiment and safe problems, environmental problems and instruments' management after experiment [4]. The division of the work mission of the above laboratories is very clear. And the work mentioned above is basically completed by lab teachers alone. Apparently, there is no division of labor; especially that large equipment maintenance is all in the charge of themselves. Generally, equipment manufacturers won't come to school once beyond one-year's maintenance period, because of insufficient money for subsequent maintenance equipment.

The fourth point is the stability of the experimental team. The internal laboratory personnel of University of Nuremberg, Germany, coordinate precision workshop laboratory is relatively stable, because of Germany's reasonable social security and better staff welfare. All laboratory personnel have their own cars and houses that they can bury themselves into work, with great concentration to do their job well, and rarely think of getting a degree, or title on purpose. They just need to be trained to work for the job. Laboratory personnel's tasks are clearly defined without quantitative, rigid index, but must be finished in high quality to ensure the laboratory research and teaching activity work well [5]. In our Shanghai University, because of the limitation of academic qualifications and titles, and treatment of laboratory staff is generally low, this is the main reason that makes teachers not settle down to work. With the development of the educational reform in our school, further enhancing and improvement of the laboratory staff's working environment and living conditions play an important role in the stability of working team, enhancing the level of experimental teaching and the effect.

\section{RECOMMENDATIONS}

From the different aspects of the above a simple comparison, you can find that our faculty's laboratory building have a lot to be improved. Hence, I come up with some superficial ideas. Firstly, the scientific planning and construction of laboratory; secondly, expanding the source of laboratory funds; thirdly, explicit and detailed laboratory position settings and responsibilities; fourthly, improving the treatment of laboratory personnel to strengthen the stability of the laboratory team and improve level of laboratory construction in different aspects. Then further improvement of practical ability and innovative ability of College students can be achieved.

\section{SUMMARY}

And the key point to the improvement of Mechanical Engineering College Students' ability is scientific and reasonable arrangement of practice teaching, especially in training plan framework of high level laboratory exercise [6], which should also be listed as the key indicators in our department training plan and assessment of teaching quality in future. Modern professional mechanical and electrical control and automation combined with each other much more closer than before. The feature of specialty is professional knowledge, involving multidisciplinary, research and produce's alternative development, experimental equipment flexibility and strong exploitability, which is suitable for the construction of some comprehensive laboratories, concentrates on validation, comprehensive, development and innovation experiment project and would carry out cooperation and exchanges among various laboratories.

Laboratory construction is a key point in the introduction of Nuremberg, Germany advanced college education mode to which will be paid more attention. It not only has the function of university laboratory in Nuremberg, Germany, but also conforms to the undergraduate students of our college and the DMAE training plan. It should also reflect the advanced nature of the experimental equipment and construction planning. The laboratory shall include mechanical engineering technology, logistics engineering, electronic technology, information technology, system engineering, control engineering, sensor technology, intelligent technology and etc. The laboratory can establish new courses and graduate courses to support college teaching reform and enhance of college level.

According to 2015 Baoshan campus's relocation of the Eastern District Development plan of Shanghai University DMAE and School of Mechatronic Engineering and Automation, and to meet the needs of mechanical professional senior technical personnel training, we can appropriately introduce Nuremberg University Laboratory mode and make the blueprint for the future of laboratory high-level planning. But this requires us to improve present laboratory equipment, and laboratory hardware conditions and the introduction of high level laboratory personnel. Considering laboratory construction should have to be adapted to the teaching reform of advanced, more comprehensively for the students to provide experimental condition of independent innovation. This paper presents a plan to build a laboratory which is integrated laboratory for testing and measuring of high level processing and manufacturing with University of Nuremberg, Germany in new campus.

\section{ACKNOWLEDGEMENT}

This research work was supported by National Key Technology Support Program of China (Grant No. 2015BAF10B01) and Science and Technology Commission of Shanghai Municipality (Grant No.15111104002 \& 15111106302).

\section{REFERENCES}

[1] Zhu Yuhua. Study of German University laboratory enlightenment[J]. Research and Exploration in Laboratory. pp. 129-132, Dec 2007.In Chinese.

[2] Xu Guoxiang, et al. Practice and Thinking on improving the level of laboratory construction[J]. Research and Exploration in Laboratory. vol 26:5, pp. 115-118, 2007.In Chinese. 
[3] Du Benxin. Exploration and practice of the construction of laboratory team in Research Universities[J]. Journal of Beihang University(social science edition), pp. 112-115, Nov 2012.In Chinese.

[4] Wang Ximing. Analysis and reference of German University of Applied Science and technology experimental teaching characteristics[J]. Journal of West Anhui University, pp. 42-45, Oct 2010.In Chinese.
[5] Sun Linge, Lu Junxian, Wang Aihua. Strengthen the understanding and thinking of the construction and management of University Laboratory[J]. Experimental Technology and Management, vol. 26:7, pp. 145-148, 2009.In Chinese.

[6] Guo Dongcai. Exploration and practice of experimental teaching and scientific research of interactive mode[J]. Research and Exploration in Laboratory, vol. 26:12, pp. 83-85, Dec 2007.In Chinese. 